\title{
Progress towards elimination of leprosy as a public health problem in India and role of modified leprosy elimination campaign
}

\author{
N. S. DHARMSHAKTU, B. N. BARKAKATY, \\ P. K. PATNAIK \& M. A. ARIF \\ Leprosy Division, Dte GHS, Nirman Bhawan, New Delhi, India
}

\section{Accepted for publication 27 September 1999}

\begin{abstract}
Summary India (population 943 million) has seen a highly significant decrease in the prevalence of leprosy since the introduction of multi-drug therapy (MDT) in 1981. From a prevalence rate of 57/10,000 of the population in March 1981, the figure has declined to 5.2/10,000 in March 1999. This was possible due to the creation of a completely vertical (specialized) inf rastructure for leprosy control in the 218 endemic districts of the country and skeleton vertical staff in the remaining districts, coupled with the recruitment of additional staff on contract basis to provide MDT through vertical staff in endemic districts and mobile treatment units in the moderate and low endemic districts. Despite all efforts, however, new case detection has not shown a decline over the last 14 years due to the presence of hidden (and undiagnosed) cases. Therefore, in order to intensify and hasten progress towards elimination (less than 1 case per 10,000 of the population) in the whole country, it was decided to implement a massive leprosy elimination campaign (LEC) in all the States/Union Territories (UTs). The reports of 22 States/UTs indicate that 415 out of the total of 490 districts in the country were covered by modified LEC (MLEC), with $85 \%$ coverage of the population. The campaign used in India was modified from the pattern previously described by the World Health Organization. The detection of hidden or suspected cases took place within a short, intensive period of 6-7 days and relied heavily on house-to-house searches by General Health Care staff trained in leprosy detection and confirmation was made by appropriately trained staff. This MLEC received widespread Government and public support, resulting in the detection of 454,290 hidden cases of leprosy, whilst providing training to a large number of General Health Care staff and volunteers and creating widespread awareness about leprosy and the availability of treatment free of charge for all cases. This programme proved to be one of the most successful health care interventions undertaken in India in recent years, particularly in the states of Bihar and Orissa. Although a few states in India are unlikely to reach the current WHO goal of elimination before end of the year 2000, the results of the MLEC strongly support the possibility that elimination levels will be achieved in the majority of states by the end of the year 2000 and at national level by the end of the year 2002 .
\end{abstract}




\section{Introduction}

India, with a population of 943 million, has over $60 \%$ of the global total of leprosy patients. ${ }^{1}$ After the implementation of the National Leprosy Eradication Programme (NLEP) in 1983, the district has been taken as the main operational unit by forming a District Leprosy Society and brought under coverage for free multi-drug therapy (MDT) services in a phased manner by building adequate vertical infrastructure. By 1995-1996, all districts of the country were covered with MDT, as a result of which there has been a sharp decline in the number of patients. The prevalence rate of leprosy in India has fallen from 57/10,000 of the population in 1981 to 5·2/10,000 in March 1999. A total of $8 \cdot 84$ million patients have been cured with MDT since the inception of the programme. Disability and ulcer care services, including reconstructive surgery facilities, have been strengthened and Special Action Projects for Elimination of Leprosy (SAPEL) introduced in difficult areas. The Leper's Act of 1898 has been repealed. Information-Education-Communication (IEC) material and learning material for health staff has been supplied to all the districts. The Modified Leprosy Elimination Campaign (MLEC) described below has already been launched in all the States/UTs. ${ }^{2}$

Despite a sharp reduction in disease prevalence, the annual new case detection rate has remained more or less the same in the last one and a half decades. However, it should be noted that over-diagnosis is increasing to some extent for several reasons, including higher community awareness. Considering i) the importance of community diagnosis of leprosy, ${ }^{3}$ ii) the extent of the leprosy problem in this vast community, iii) the number of General Health Care (GHC) staff requiring training, iv) the level of required public awareness about leprosy and $v$ ) the existence of free treatment facilities provided by Government and Non-Government Organizations, it was decided to undertake package of three activities in all States/ UTs within a defined period of time. This package consisted of orientation training of all health staff, building community awareness about leprosy and on availability of free MDT services followed by an intensive search in the entire population for a period of 6 days. The MLEC was then first implemented in the state of Tamil Nadu in February 1997 and this was implemented successfully in the state. The mid-term appraisal of this World Bank-supported NLEP project, undertaken in April 1997, recommended implementation of the same in other states. ${ }^{4}$ The need for MLEC in all states was further discussed at a meeting of State Health Secretaries under the chairmanship of the Union Health Secretary in July-August $1997 .^{5}$ Based on the suggestions of the above meeting, the Government of India decided to implement MLEC in all States/UTs. The WHO recommendation for a reduction of duration of treatment for multibacillary (MB) patients from 24 to 12 months and the introduction of single-dose ROM therapy (rifampicin, ofloxacin, minocycline) for single skin lesion patients, ${ }^{6}$ was also accepted for implementation from 1 November 1997 under the NLEP in India. ${ }^{7,8}$ The approach adopted for the implementation of MLEC, its results, lessons learned and implications for the future are presented in this paper.

\section{Reasons for MLEC implementation}

Implementation of MLEC was considered important in view of the following factors: i) stigma associated with the disease in the community leading to misconception, a tendency to hide the disease and indifference; ii) lack of interest in leprosy shown by GHC workers in the past; iii) a small scale campaign achieves only limited participation by health staff, 


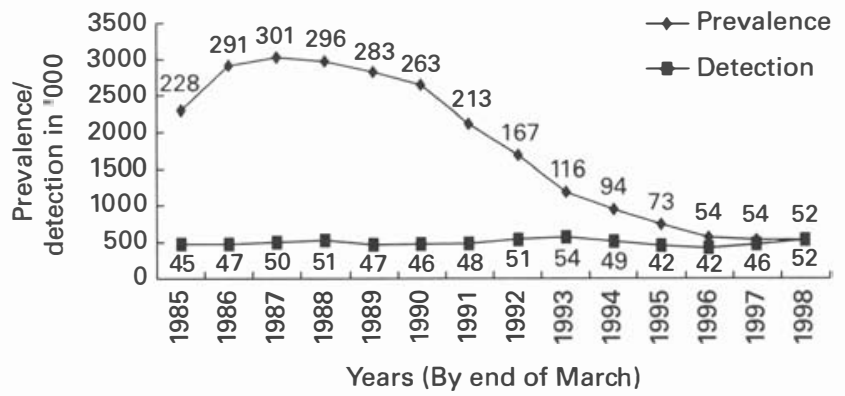

Figure 1. 1985-1998 trend.

community and other agencies; iv) the MLEC approach increases the outreach of the programme; v) annual new case detection in the last 14 years has remained the same (Figure 1), indicating hidden cases; and vi) effective MDT drugs are freely available from the WHO.

\section{Objectives of MLEC}

The basic objectives of MLEC are to i) create mass awareness about facts of leprosy and availability of free MDT treatment, ii) give orientation training on leprosy to all GHC staff, village level workers and volunteers and iii) make use of awareness and training for detecting hidden or suspected cases within a short and specified period of 6-7 days.

Consequently, it was anticipated that people would come forward for diagnosis voluntarily, the stigma against the disease would decrease and free MDT be made available from the nearest health facility.

\section{Strategy adopted for MLEC}

1. Supply of IEC material and orientation training to all Government Medical Officers, Health Supervisors and Health Workers 2-3 months in advance.

2. Mass Awareness Campaign in the States/UT 2-3 months in advance of search operation to cover the entire population. Extensive use of radio, TV, cinema, print media, posters, banners, hoardings, handbills, meetings, rallies etc. to be made, together with involvement of a large number of other field level staff, village workers, teachers, volunteers and scouts. Priority was given throughout to personal contact and coverage of rural populations.

3. Extensive house-to-house search operation for a short period of 6 days to detect suspected leprosy cases, who are to be medically examined for confirmation, simultaneously or within a short time after search, and to put them on MDT if confirmed as leprosy. Each search team comprised one male and one female worker and a local volunteer from the village. 


\section{Work plan}

1. Extensive planning was initiated 6 months in advance.

2. Execution of MLEC was done through a 3-month period ending with 6 days search.

3. Confirmation of suspected cases and treatment with MDT.

\section{Planning process at the national level}

The planning process of MLEC at the national level included the following important steps:

1. Meeting of State Health Secretaries and development of detailed guidelines.

2. Submission of individual plan by the State/UT.

3. Further discussion of individual state plans.

4. Release of funds to districts.

5. Preparation of prototype IEC kit and distribution.

6. Ensuring availability of drugs for all States/UTs.

\section{Methodology adopted for implementation of MLEC in the state/UTs}

The MLEC implementation was carried out in the states in three phases namely, preparatory phase, implementation phase and reporting phase for the analysis of achievements, ensuring treatment of all detected cases and reporting achievements. Detailed activities undertaken in the preparatory phase and implementation phase were as follows:

PREPARATORY PHASE

1. Meeting with heads of related departments under the chairmanship of the Health Minister or Chief Secretary.

2. Development of a mechanism for co-ordination, monitoring and supervision.

3. Workshop for district level officers and representatives from other departments/ organizations.

4. Development of district micro plan by district leprosy officers based on guidelines, proforma and formats supplied by Central Government.

5. Training of trainers, medical officers and peripheral staff including searchers and volunteers.

6. Involvement of community participation at district, 'panchayat' and village level.

7. Intensifying community awareness activities through various media for 1 month before starting the actual search.

The details of public awareness activities included:

1. Audio-visual media: TV (film spots, messages), radio (messages, jingles), cinema slides, microphone announcements in street, villages and bazaars.

2. Print media: advertisements in newspapers, handbills, tinplates, banners, hoardings wall paintings, diagnostic cards, stickers, rickshaw plates, bus panels etc.

3. Folk media: street plays, cultural programmes in the village, folk announcements, drum beats etc. 
4. Interpersonal communication: information through health workers, group discussions and talks on leprosy for various groups.

5. Other media: mobile van, rallies, exhibitions, public meetings with 'panchayat' and village leaders.

\section{IMPLEMENTATION PHASE FOR DETECTION OF SUSPECTED PATIENTS}

A team of two searchers (one male, one female), along with one local volunteer from the village conducted a rapid survey for identification of suspected cases. Each team on average covered 300-500 population per day (60-100 families or 1800-3000 population for 6 days).

Vertical staff was kept mobile for support and guidance of the searchers and for confirmation of cases. State level, divisional level and district officers supervised the search activities. A control room was established in each state and district headquarters during the search period. The senior state government officials supervised the campaign in all districts The officers of the NLEP from Leprosy Division, Directorate General of Health Services, NLEP Consultants, Regional Directors of Health and Family Welfare, officers of Central and Regional Leprosy Research and Training Institutes, (Chengalpattu, Gauripur, Raipur and Aska) also supervised the campaign in various states. Officers of WHO also visited the campaign activities in some states.

\section{Results and discussion}

The geographical coverage of MLEC in the 22 States/UTs that implemented MLEC is shown in the map. A total of 9.38 lakh doctors, health supervisors and health workers were given orientation on leprosy. The net outcome of search indicated that a total of 2.86 million suspected patients were identified and 454,289 cases were confirmed as leprosy. Of those confirmed, $55.8 \%$ were $\mathrm{PB}, 32.5 \%$ were $\mathrm{MB}$ and $11.7 \%$ had a single lesion.

The result of various community awareness activities undertaken was impressive, with excellent co-operation from the public during the search period. People expressed no inhibition in attending the special clinics opened for case confirmation and subsequently in attending leprosy clinics or outpatient departments. The public awareness and knowledge of leprosy improved and public participation during leprosy exhibitions was excellent. There was a massive improvement in voluntary reporting of suspected cases. The statewise breakup of new cases detected through search is shown in Table 1. This indicates an achievement of a total of 454,289 new cases, which is more or less the same as the total normally detected in the entire country in 1 year.

The average annual case detection in the last 4 years in comparison to the case detection by MLEC in states with very good MDT coverage and performance in the past is shown in Figure 2. It shows that there were significant numbers of hidden cases, even in states that have had good vertical programmes for the last 12 years, (ranging between 20 and $48 \%$ of annually recorded cases) as in Maharashtra, Andhra Pradesh, Tamil Nadu, Karnataka, Pondicherry and Gujarat.

The average annual new case detection in the last 4 years in comparison to case detection by MLEC in states with poor and satisfactory MDT programmes in previous years is shown in Figure 3, which indicates that the number of hidden cases is still much higher in the states with satisfactory MDT programmes for the last 4 years, for example Orissa, Uttar 
Table 1. Statewise breakup of new cases detected by MLEP

\begin{tabular}{|c|c|c|c|c|c|c|}
\hline \multirow[b]{2}{*}{ SNO } & \multirow[b]{2}{*}{ Name of State/UT } & \multicolumn{2}{|c|}{ Population in lakhs } & \multirow{2}{*}{$\begin{array}{l}\text { No. of suspected } \\
\text { cases }\end{array}$} & \multirow{2}{*}{$\begin{array}{c}\text { No. of confirmed } \\
\text { cases }\end{array}$} & \multirow{2}{*}{$\begin{array}{l}\text { No. of single } \\
\text { lesion }\end{array}$} \\
\hline & & Enumerated & Examined & & & \\
\hline 1 & Andhra Pradesh & $682 \cdot 32$ & $621 \cdot 83$ & 196,040 & 18,742 & $7432(39.65 \%)$ \\
\hline 2 & Assam & $245 \cdot 10$ & $195 \cdot 01$ & 45,255 & 4054 & $212(50 \cdot 2 \%)$ \\
\hline 3 & Bihar & $927 \cdot 09$ & $749 \cdot 26$ & 617,362 & 206,495 & $9401 \quad(4.6 \%)$ \\
\hline 4 & Chandigarh & $3 \cdot 31$ & $2 \cdot 39$ & 1,191 & 112 & 0 \\
\hline 5 & D \& N Haveli & 1.47 & 1.04 & 631 & 149 & $29(19.46 \%)$ \\
\hline 6 & Daman \& Diu & $1 \cdot 30$ & $1 \cdot 11$ & 596 & 79 & $13(16.5 \%)$ \\
\hline 7 & Goa & 2.97 & $2 \cdot 91$ & 348 & 72 & 0 \\
\hline 8 & Gujarat & $406 \cdot 86$ & 323.76 & 47,669 & 3648 & $889(24.4 \%)$ \\
\hline 9 & Haryana & $38 \cdot 53$ & $32 \cdot 54$ & 5402 & 302 & $36(11.9 \%)$ \\
\hline \multirow[t]{2}{*}{10} & a) Jammu Divn & $38 \cdot 59$ & $25 \cdot 43$ & 2448 & 857 & $332(38.74 \%)$ \\
\hline & b) Srinagar Divn & 40.07 & $23 \cdot 80$ & 4658 & 152 & $5(3.2 \%)$ \\
\hline 11 & Karnataka & $463 \cdot 60$ & $366 \cdot 45$ & 72315 & 9881 & $4240(42.9 \%)$ \\
\hline 12 & Kerala & 303.79 & 244.92 & 129,419 & 2151 & NR \\
\hline 13 & Madhya Pradesh & $847 \cdot 57$ & $554 \cdot 67$ & 141,362 & 20,248 & $2268(11 \cdot 2 \%)$ \\
\hline 14 & Maharashtra & $871 \cdot 81$ & $741 \cdot 86$ & 303,404 & 20,858 & $8774(42 \cdot 1 \%)$ \\
\hline 15 & Nagaland & $14 \cdot 55$ & $13 \cdot 02$ & 441 & 26 & $3(11 \cdot 5 \%)$ \\
\hline 16 & Orissa & 338.58 & 289.61 & 416,604 & 62,844 & $12,098(19 \cdot 3 \%)$ \\
\hline 17 & Pondicherry & $9 \cdot 14$ & $6 \cdot 83$ & 3332 & 254 & $88(35.6 \%)$ \\
\hline 18 & Punjab & $236 \cdot 33$ & $27 \cdot 22$ & 5622 & 629 & $66(10.5 \%)$ \\
\hline 19 & Sikkim & 3.96 & $2 \cdot 86$ & 1052 & 61 & $8(13.11 \%)$ \\
\hline 20 & Tamil Nadu & 528.44 & $378 \cdot 70$ & 248,660 & 12,797 & NR \\
\hline 21 & Uttar Pradesh & $1470 \cdot 83$ & $1249 \cdot 34$ & 420,756 & 55,401 & $4926(8.89 \%)$ \\
\hline \multirow[t]{2}{*}{22} & West Bengal & 733.46 & $594 \cdot 15$ & 193,700 & $34,478^{*}$ & $2300 \quad(6 \cdot 67 \%)$ \\
\hline & Total & 8209.67 & $6448 \cdot 71$ & $2,858,267$ & 454,290 & $53,120(11.69 \%)$ \\
\hline
\end{tabular}

*4797 detected later out of 21,439 suspected cases not added.

$\mathrm{NR}$, not reported separately.

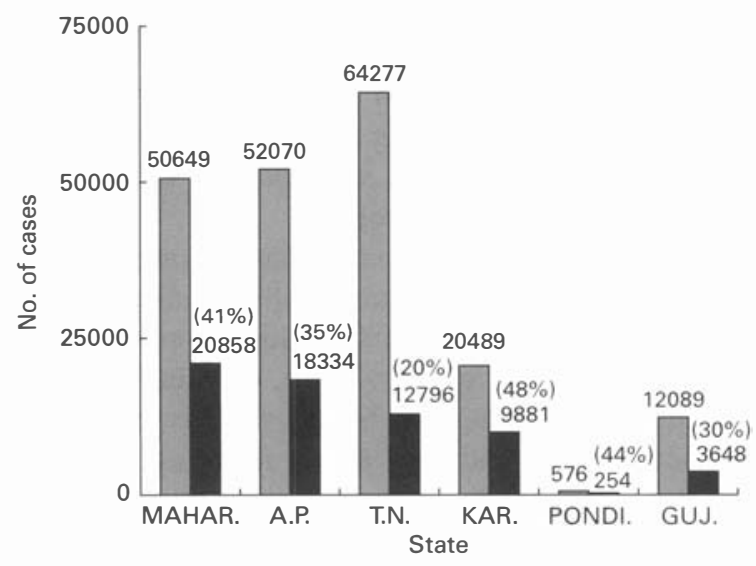

Average annual case detection in last 4 years in states with very good performance

Case detection by MLEC in 6 days

Even the states with very good MDT programmes for the last 12 years showed $20-48 \%$ new case detection in 6 days compared to their annual average case detection in the last 4 years.

Figure 2. Comparison of case detection by MLEC and routine survey: states with very good MDT coverage. 


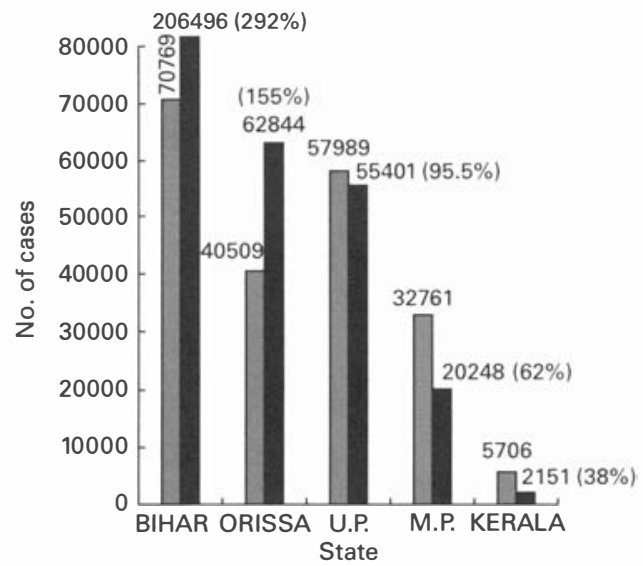

Average annual case detection in last 4 years in states with poor and satisfactory MDT programme

Case detection by MLEC in 6 days

- The states with satisfactory MDT programme for the last 4 years (Orissa, U.P., M.P., Kerala) showed 38-155\% new case detection in 6 days compared to their annual average case detection in last 4 years.

- The state with poor MDT programme for the last 12 years (Bihar) showed $292 \%$ new case detection in 6 days compared to the annual average case detection in last 4 years.

Figure 3. Comparison of case detection by MLEC and routine survey: states with poor and satisfactory MDT programmes.

Pradesh, Madhya Pradesh and Kerala, ranging between 38 and 155\% of annually recorded cases. The number of hidden cases was found to be highest in the state with a poor MDT programme in the past, i.e. Bihar, where detection by MLEC was $292 \%$ of the annually recorded cases. Surprisingly, implementation of MLEC was highly successful in this state, where the public response was overwhelming and the participation of health staff excellent. The state governments of Bihar and Orissa reported that MLEC was the most successful intervention ever launched in the health sector.

The average new case detection in the last 4 years in low endemic states in comparison to case detection by MLEC is shown in Figure 4, which indicates that even in low endemic states on the MDT programme for over 4 years, the hidden cases were significant in number, e.g. 59\% of annually recorded cases in Chandigarh, 65\% in Punjab, 149\% in Haryana and $225 \%$ in Assam. The higher percentage of hidden undetected cases of leprosy in Assam is attributed to the difficult terrain and civil unrest resulting in unsatisfactory detection of early cases.

\section{LESSONS LEARNT FROM MLEC}

1. In order to create public awareness about a disease like leprosy, which is associated with stigma, and for involvement of general health staff, a campaign approach with messages and instructions from state level to the districts and various departments is essential to ensure proper detection of patients and follow-up for treatment. 


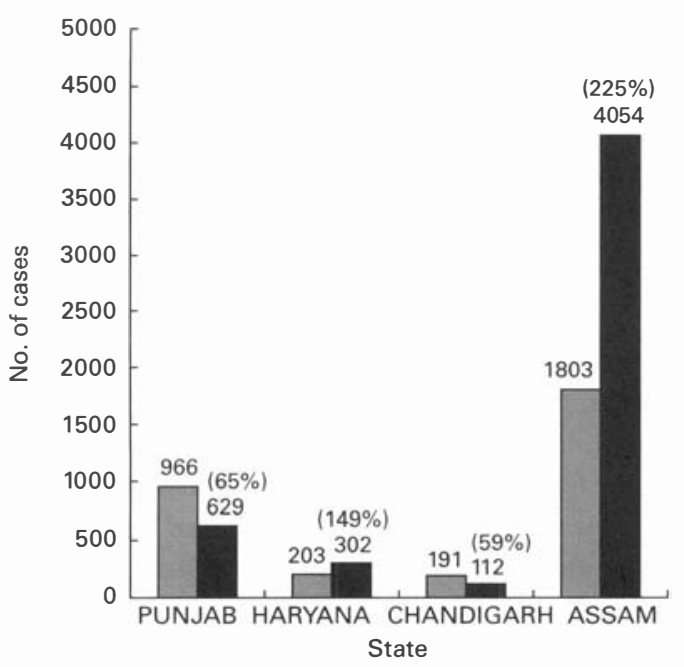

Average annual case detection in last 4 years in low endemic state with satisfactory MDT coverage

Case detection by MLEC in 6 days

The state with a satisfactory MDT programme for about 4 years and identified as low endemic, showed $59-225 \%$ new case detection in 6 days compared to their annual average case detection in the last 4 years.

Figure 4. Comparison of case detection by MLEC and routine survey: low endemic states.

2. The orientation training of GHC staff in leprosy accomplished through the MLEC approach is well accepted, and can be taken up over a short period in the entire state.

3. The MLEC approach is much more effective and quicker in yielding results compared to the conventional approach of routine searches in smaller segments of the population at different intervals. General awareness created through the campaign approach leads to mass mobilization.

4. Proper planning, political and administrative support from state headquarters is essential to ensure success of the campaign.

5. Detection of large numbers of leprosy cases should not be confused with a leprosy epidemic in the country. Such detection in a short span of 6 days search was possible mainly because systematic attempts were made to detect the hidden cases and the people came forward as a result of massive awareness. Such cases had not previously been detected because of residence in remote or difficult areas, or not reported due to ignorance or stigma.

In Orissa, for example, the prevalence of leprosy in a regularly surveyed population is $20 / 10,000$, as accomplished by vertical staff over a longer period of time. In the population covered by MLEC the PR is also 21/10,000, which is detected with involvement of volunteers and community in only 6 days. Therefore detection of this large number of cases should not be misunderstood as an epidemic of the disease.

Stigma against leprosy patients has been a serious hindrance in people coming forward for treatment openly. The picture has now changed significantly and this may be attributed to the massive awareness programme and free MDT services made available. 
RESULTS IN RELATION TO FUNDS PROVIDED

The achievements for every 100,000 rupees (US \$2439) released were: i) 735 new suspected cases identified, ii) 116 new patients confirmed and put on MDT, iii) 226 persons given orientation training (MO, supervisor, health worker and volunteer), iv) intensive awareness created in the community and v) learning material provided to different categories of staff.

\section{CONCLUSION}

If the strategic programme activities are implemented in a package form to be conducted in a definite time frame with commitment of the States/UTs, the output can be productive as witnessed under the MLEC in India. The figure of US \$2439 would cover 116 patients detected and put on treatment (UK Sterling $£ 13$ per patient), and 226 persons given orientation training on leprosy. Seven hundred and thirty-five persons were identified as suspected leprosy cases by personal contact with them and their families and the overall effect of this campaign on public awareness and political commitment can be considered remarkable. It also bears emphasis that without this campaign, many of these cases would not have been detected and treated at a reasonably early stage of their disease, with the obvious risk of progression and long-term disability.

\section{Acknowledgements}

This massive campaign would not have been possible without support provided by Central and State Governments and assistance from the World Bank, WHO, the Director General of Health Services and officers of the Ministry of Health and Family Welfare. The authors are grateful to Dr Salim Habayeb, World Bank, Washington and Dr S. K. Noordeen, WHO, Geneva for their suggestions and guidance. The Government of Tamil Nadu played an important leading role by implementing MLEC first. The support provided by DANIDA and other international and national Voluntary Organizations including Doordarshan, AIR and PRESS was invaluable. The staff of the Leprosy Division, Directorate General of Health Services, administrative and finance divisions of Ministry of Health, all played a crucial role in planning, providing technical and administrative guidelines and ensuring the timely release of funds to District Leprosy Societies. The Health Secretaries, Directors of Health Services of the states involved, State Leprosy Officers, District Collectors, Chief Medical Officers, District Leprosy Officers and all other members of NLEP and General Health Care staff played a crucial role. The co-operation and active involvement of all State Government officials, the NLEP/WHO Coordinator in Bihar, NLEP Consultants, Regional Directors of Health and Family Welfare, officials of General Health Care, the officers of CLTRI, Chengalpattu and Regional Leprosy Training and Research Institutes, Raipur/Gauripur/ Aska, are gratefully acknowledged for their contribution to the success of this campaign.

\section{References}

1 WHO. Weekly Epidemiological Record, 22nd May, 1998, p. 155.

2 Dharmshaktu NS. Progress of NLEP in India with special reference to modified leprosy elimination campaign. Paper presented at International Leprosy Congress, Beijing, 7-12 September 1998.

3 Dharmshaktu NS. A guide on leprosy. 1995, p. 102. 
${ }^{4}$ Report of mid-term appraisal of World Bank supported NLEP project, 7-19 April, 1997, Dte. G.H.S., New Delhi.

5 Minutes of the meeting of State Health Secretaries on NLEP held in New Delhi, July-August, 1997 to discuss findings and recommendations of mid-term review and action required for strengthening the programme.

6 WHO. Report of the third meeting of the Leprosy Elimination Advisory Group, Geneva, 16-17 July, 1997 , p. 9.

7 Recommendations of National Leprosy Experts group meeting to review the chemotherapy of leprosy and review the recommendations of LEAG, WHO on Chemotherapy of leprosy, 28 July 1997, New Delhi.

8 Modified guidelines on MDT regimen to be followed under NLEP from 1 November 1997, No. L-19025/6/97-Lep., dated 28 August, 1997. 